\section{Amaldi International Prize}

\section{for a High School Physics Textbook CALL FOR NOMINATIONS}

The Edoardo Amaldi Foundation, with the joint sponsorship of the European Physical Society (EPS), seeks nominations for an ECU 20000 prize in memory of contributions by Edoardo Amaldi and his wife Ginestra to physics and science teaching in high schools. The prize will be awarded for the first printing of a high school textbook in physics (14- to 18-year old students) published between 1 January 1987 and 30 September 1993. The author, who must be European and working in Europe in a country whose national society is a member of EPS, will receive ECU 16000; the publisher receives the balance. Innovation in high-school teaching is a prime consideration.

Interested authors or publishers (with an author's consent) are invited to apply by sending, by 30 September 1993, two copies of the volume to: Amaldi International Prize Secretariat, Via Mazzini, 62, I-29100 Piacenza. Applicants will subsequently be asked to send five additional copies to Members of the Jury nominated jointly by the Foundation and EPS.

The Jury can decide not to award the Prize, which cannot be shared. It will be handed over in Piacenza in Spring 1994 and the textbook would be expected to carry a special wrapper bearing an inscription and the Prize's logo.

\section{SCUOLA NORMALE SUPERIORE \\ Saint Gobain \\ Post-doctoral Fellowship \\ on the \\ Physics of Disordered Materials}

Applications are invited for a Saint Gobain post-doctoral fellowship tenable for a calendar year at the Scuola Normale Superiore di Pisa, starting from 1st September 1993. This fellowship carries a stipend of $27,000,000$ Italian Lire per annum, and may be renewed for a second year.

Applications addressed to Prof. E. Picasso, Director, Scuola Normale Superiore, Piazza dei Cavalieri 7, I-56126 Pisa, Italy, should reach Pisa no later than 31 May 1993.

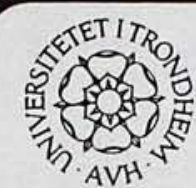

\section{Professorship in Theoretical Particle Physics}

is vacant at the Department of Physics, College of Arts and Science, University of Trondheim. A main activity in the theory group at the department is in elementary partiele physics and astrophysics.

We want to hire a person with a strong background in theoretical particle physics, who can strengthen our activity in CERN-related research. It will be considered an advantage if, in addition, the appointee can support activities in high-energy astrophysics and cosmology.

Applications should include a curriculum vitac and a list of publications, in 6 copies, and be sent to

\section{Universitetet i Trondheim, AVH,}

Personalkontoret, N - 7055 Dragvoll, Norway,

before May 3, 1993. Please quote reference number 1663 in the application.

Within June 3, 1993 the applicants are furthermore supposed to provide 5 copies of the scientific papers they consider most important. The number of papers sendt in should normally not excecd 10. A description of these papers, in six copies, should also be: included.

For a more detailed description of the position and further information

about the application procedures, interested applicants should contact

Professor Kjell Mork, Department of Physics,

University of Trondheim, AVH, N-7055 Dragvoll, Norway.

tel.:+47-7-591865 Fax.:+ 47-7-59 18 52; e-mail:kjell mork@avh.unit.no.

\section{Venjamin Chebotaev}

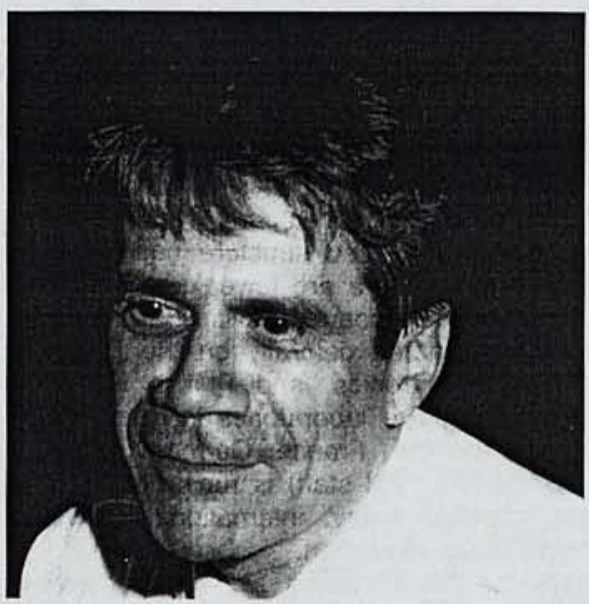

Venjamin Chebotaev died of a heart attack on 2 September 1992 at the age of 57 . He was on a short visit to Tucson, Arizona, while spending a year in Munich on an Alexander von Humboldt award. Laser spectroscopiste were deeply shocked for they lost one of the most talented colleagues, who was not only collaborative and inspiring but also an ou standing teacher and a warm-hearted and lively person.

Venjamin was born in Knibishev located near the mid-point of the Volga River. He inherited the spontaneous openness of his countrymen. World War II took him to Novosibirsk where he graduated from the Institute of Electronics in 1960, and received his doctoral degree in physics and mathematics in 1972. He then set about building up a laser spectroscopy group at the Institute of Thermophysics in Akademgorodok-Novosibirsk, eventually becoming the Vice-Director. $\mathrm{He}$ was named only a year before his death as the Director of the Institute of Laser Physics which had been specially created for him.

Chebotaev's achievements over the years can be viewed as a string of precious pearls of ever increasing beauty. The hollow cathode laser developed by him in 1965 was the first laser to be operated in Siberia. Fol lowing Lamb's theory of non-linear effects , the absorption of gas lasers, Chebotaev (simultaneously with Lee and Scolnick in the USA) demonstrated intercativity and later extracavity Doppler-free resonances in different gases. This was a cornerstone in the development of Doppler-free saturation spectroscopy, later applied worldwide to study the properties of atoms and molecules with the highest precision. At the same time Chebotaev observed optical hysteresis and bistability using nonlinear absorption (the latter becoming important in optical computers and storage devices).

In 1970, Chebotaev showed that two-photon absorption was a new and very powerful technique for Doppler-free spectroscopy. It turned out to be one of the most important methods for ultra-high precision, particularly in hydrogenic systems. He also measured the tiny recoil effect in the absorption of photons by atoms. Following Ramsey's approach for separated oscillatory field resonances, Chebotaev was able to transfer the idea to separated coherent optical fields, and detected signals in two-and three-level systems, seeing two-photon resonances and spatial optical echoes. 
Step-by-step, Chebotaev's laboratory became engaged in superhigh-resolution spectroscopy and its application to fundamental problems. The rich harvest of the 1980's included the observation of the temperature red shift due to the second-order Doppler effect, the direct observation of resonance narrowing by means of very cold particles, and the construction of frequency standards with excellent short- $\left(10^{-16} \mathrm{~s}\right)$ and long-term $\left(10^{-14} \mathrm{~s}\right)$ stabilities. Finally, as a coronation, he developed an optical clock for a time standard based on frequency measurements in the infrared and optical ranges.

Chebotaev's feeling for future developments is impressively demonstrated by his theoretical study of cold ions in a trap; he realised the possibility of Wigner crystallization long before the effect was observed. One should also mention Chebotaev's interest in applications of lasers in fields ranging from metrology and astrophysics to material sciences and medicine. For instance, the first attempt to correct the focal length of the eye by the Fjodorov method of cornea ablation with a laser knife was prepared under his reful guidance.

Venjamin Chebotaev created a school of alented scholars who matured to scientific independence in an inspiring and open atmosphere: it is no wonder scientists from all over the world visited. The Vavilov conferences held in Akademgorodok are remembered as the finest meetings in laser science; the annual German-Soviet Laser Seminar from 1969 to the late-1980's was strongly supported by him. He initiated contacts between younger scientists in both countries, something which was not trivial at the time. The visibility of laser physics and spectroscopy was greatly enhanced by his monograph Nonlinear Laser Spectroscopy, together with V.L. Letokhov, that remains today a classic textbook.

Chebotaev received many awards and honours, notably the 1978 Lenin Prize and the 1984 Charles Hard Townes Prize; he was a fellow of the Optical Society of America. A remarkable man, full of new ideas and inspiring his colleagues by open discussion, z possessed the sense and feeling to aim tor discoveries of importance. He was a ifted teacher, guiding his scholars and shielding them against daily mishaps while all the time radiating his joy of life. His early loss is a greatly sorrowing: with Venjamin's wife Tanja and his daughter Marina, we share our deep sympathy.

\section{G. zu Putlitz, T.W. Hänsch} Heidelberg

\section{ERRATA}

In the item "LEST Moves Ahead" published last December [Europhys. News 23 (1992) 206 ] the Editor referred to a meeting in 1991 of OECD ministers. This should have been the Experts Meeting of the OECD's Megascience Forum (see page 48) held in October 1992 at which LEST was the only groundbased solar project considered. In the LEST article on page 203, the Editor in converting acronym's referred to the National Solar Observatory's $1.5 \mathrm{~m}$ telescope on Kitt Peak as the Big Bear Solar Telescope. The Big Bear Solar Observatory is in fact a $0.4 \mathrm{~m}$ multiaperture telescope located at Big Bear Lake.

$\mathbb{R}(\mathbf{R})$

Institut de Physique et Chimie des Matériaux de Strasbourg

PROFESSOR POSITION IN OPTICS AND OPTOELECTRONICS

Université Louis Pasteur, Strasbourg I, France

The University Louis Pasteur of Strasbourg (France) is seeking candidates with excellent research records and a clear teaching capability for a position of Full Professor in Optics and Optoelectronics, effective September 1, 1993.

Applicants with research interests in the following areas are encouraged to apply: nonlinear optics, especially in optical phase conjugation and photorefraction, and in nonlinear optics of confined structures and novel materials. The candidates should have a clear experience in both applied and pure optics besides a good knowledge of material science.

Applicants must also have a strong interest in teaching modern optics at the undergraduate and graduate levels. A good knowledge of the French language is highly desirable.

Candidates should have the "qualification" asked for a University Professorship.

To receive further information concerning the selection procedure, please contact:

Roland LEVY - tel.: +33 (88) 358029

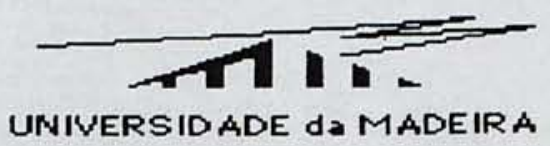

The Universidade da Madeira announces openings for professors and assistants in the fields of mathematics, theoretical and experimental physics.

The candidates for professorships and assistantships must hold, respectively, doctorate and masters degrees or equivalent.

The evaluation of candidates will be based on the scientific, pedagogical and professional achievements with preferences for experience on the following research areas: Functional Analysis, Stochastic Processes, Classical and Quantified Dynamical Systems as well as Disordered and Complex Systems.

The teaching language is Portuguese.

Candidatures, with curriculum vitae and list of publications should be directed to Presidente da Comissão Instaladora da Universidade da Madeira, Colégio dos Jesuitas, Largo do Municipio, 9000 Funchal, Portugal, and contain the following information: full name, names of parents, date and place of birth, single/maried, residential address and telephone number, academic degree with listing of corresponding courses and grade, grades obtained in first academic degree, university where this grades were obtained and dates as well as any other materials that the candidate considered as relevant for his evaluation. The deadline for application is April 15, 1993.

Annual salaries (in Escudo portugais): Full professor

$\begin{array}{ll}\text { Assoc. professor } & 5701150 .- \\ \text { Assist. professor } & 4938150 .- \\ \text { Assistants } & 3538150 .-\end{array}$

7354 550.-

3538 150.-

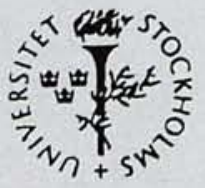

Chair in

\section{THEORETICAL PHYSICS, especially theory of gravitation and fundamental interactions (ref. number 611-96/93).}

Applications should be addressed to:

\section{Rektorsämbetet \\ Stockholms universitet \\ Personalenheten \\ Registrator \\ S-106 91 Stockholm \\ Sweden}

and arrive at the latest by May 17, 1993.

With the application should be submitted:

1. Curriculum Vitae and list of scientific putlications.

2. Short written account of scientific and pedagogical activities. From this account it should be clear which investigations, results and other achievements should be primarily considered in the selection procedure in the applicant's own view.

More information on the application procedure including when and where reprints of scientific articles should be sent can be obtained from the administrative officer in charge (Mr. U. Lindgren, phone: +46-8-163322; fax: +46-8-6125960). 